\title{
Regulation of Stress Responses and Translational Control by Coronavirus
}

\author{
To Sing Fung ${ }^{1}$, Ying Liao ${ }^{2, *}$ and Ding Xiang Liu ${ }^{1, *}$ \\ 1 School of Biological Sciences, Nanyang Technological University, 60 Nanyang Drive, \\ Singapore 637551, Singapore; tosingfung@163.com \\ 2 Department of Avian Diseases, Shanghai Veterinary Research Institute, \\ Chinese Academy of Agricultural Sciences, Ziyue Road 518, Shanghai 200241, China \\ * Correspondence: liaoying@shvri.ac.cn (Y.L.); dxliu0001@163.com (D.X.L.); Tel.: +86-21-34680291 (Y.L.); \\ +65-63162862 (D.X.L.); Fax: +86-21-54081818 (Y.L.); +65-67913856 (D.X.L.)
}

Academic Editor: Craig McCormick

Received: 3 March 2016; Accepted: 28 June 2016; Published: 4 July 2016

\begin{abstract}
Similar to other viruses, coronavirus infection triggers cellular stress responses in infected host cells. The close association of coronavirus replication with the endoplasmic reticulum (ER) results in the ER stress responses, which impose a challenge to the viruses. Viruses, in turn, have come up with various mechanisms to block or subvert these responses. One of the ER stress responses is inhibition of the global protein synthesis to reduce the amount of unfolded proteins inside the ER lumen. Viruses have evolved the capacity to overcome the protein translation shutoff to ensure viral protein production. Here, we review the strategies exploited by coronavirus to modulate cellular stress response pathways. The involvement of coronavirus-induced stress responses and translational control in viral pathogenesis will also be briefly discussed.
\end{abstract}

Keywords: coronavirus; ER stress; unfolded protein response; p38; JNK; eIF2 $\alpha$; PKR; PERK; GADD34/PP1; nsp1; translational control

\section{ER Stress Responses Regulated by Coronavirus and Its Implication in Pathogenesis}

\subsection{The Integrated Signaling Network of the Unfolded Protein Response (UPR)}

Inside a eukaryotic cell, most of the transmembrane and secreted proteins are translated, modified, and folded in the ER. The amount of proteins in the ER can fluctuate substantially when a cell is undergoing physiological changes or when it is affected by various environmental stimulations. If the protein influx overloads the protein processing machinery, unfolded/misfolded proteins will accumulate inside the ER and result in ER stress. In order to return to homeostatis, cells have evolved UPR [1], which is composed of three pathways. These pathways are initiated by three ER sensor proteins located in the ER: PKR-like ER protein kinase [1], activating transcriptional factor-6 (ATF6) and inositol-requiring protein-1 (IRE1) (Figure 1). All of them are single-pass transmembrane proteins, consisting of a luminal domain that recognizes unfolded/misfolded protein inside the ER, and a cytosolic domain that ultimately relays the signal to the nucleus and switches on a specific set of downstream genes. 


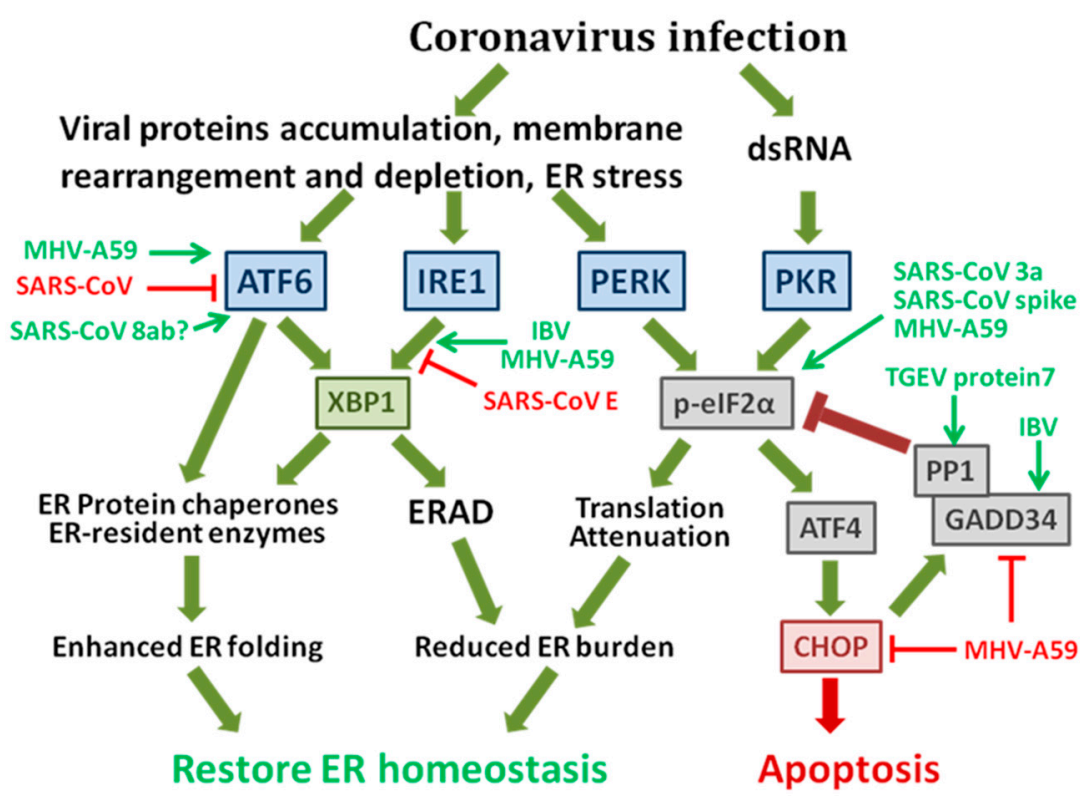

Figure 1. The induction of ER stress and UPR during coronavirus infection. Coronavirus infection induces ER stress and activates UPR. Activated ATF6 transcriptionally induces XBP1, ER chaperones and enzymes to enhance the ER folding capacity. Activated IRE1 mediates splicing of the XBP1 mRNA, whereas the spliced XBP1 protein enhances ER folding and reduces ER burden by promoting ERAD. Activated PERK mediates the phosphorylation of eIF2 $\alpha$, leading to a global translation attenuation. Signaling via the ATF4-CHOP pathway promotes apoptosis induction during prolonged ER stress. The known coronaviruses and viral proteins modulating the UPR signaling are also indicated. Green arrows are activating and red blunt arrows are inhibiting. See text for detail.

Under ER stress, oligomerization and activation PERK mediates the phosphorylation of eIF2 $\alpha$, resulting in the shutdown of global translation [2,3]. The PERK-dependent inhibition of protein synthesis limits nascent protein transport to ER lumen, thereby attenuating the protein accumulation in ER. Interestingly, some proteins are preferetially translated when eIF2 $\alpha$ is phosphorylated. One example is ATF4 [4], a transcription factor that control the expression of genes involved in amino acid metabolism and transport and redox chemistry. GADD34 is one of downstream genes triggered by ATF4. As a regulator subunit, GADD34 helps PP1 to dephosphorylate eIF2 $\alpha$, thereby limiting PERK signaling as a negative feedback loop [5]. PERK signaling will be considered as part of translational control and will be discussed in Section 3.

As for the IRE1 branch of UPR, activation of IRE1 by auto-phosphorylation activates its cytosolic RNase domain, which mediates a unique splicing event that removes an intron from the transcript of X-box protein 1 (XBP1) [6]. The spliced form of XBP1 protein (XBP1s) is then translated and imported to the cell nucleus, thereby activating the expression of UPR genes, which encode various ER protein chaperones as well as components of the ER-associated degradation (ERAD) pathway [6]. Moreover, IRE1 is also known to catalyze non-specific degradation of mRNAs associated with the ER, a phenomenon dubbed as IRE1-dependent RNA decay (RIDD) that effectively reduces the translational burden of the ER [7]. In spite of these pro-survival activities, prolonged activation of IRE1 can also activate c-Jun N-terminal kinase (JNK) and promote caspase-12 dependent apoptosis [8,9].

In terms of ATF6, increasing amounts of unfolded proteins activate the protein and lead to its translocation from the ER to the Golgi, in which the protein is sequentially cleaved by proteases. The cytosolic domain of ATF6 is then released and transported into the nucleus[10], where it induces the expression of UPR genes, such as some ER protein chaperones (calreticulin, glucose regulated protein $78 \mathrm{kDa}$ (GRP78) and GRP94), some ERAD proteins, as well as ER-resident enzymes (protein disulfide isomerase) [11]. 
With the help of several feedback mechanisms, the three UPR pathways mentioned above actually constitute an inter-related signaling network [1]. For example, XBP1 mRNA from the IRE1 branch has been shown to be induced by PERK and ATF6 when cells are under ER stress [6,12]. Moreover, both PERK and PKR could be inhibited by $\mathrm{P} 58^{\mathrm{IPK}}$, which is a downstream gene transcriptionally induced by XBP1s $[13,14]$. Finally, the expression and activation of ATF6 could be enhanced by PERK, while ATF6 may induce protein disulfide isomerase A6, which promotes the degradation of IRE1 [15-17]. Hence, the three branches of UPR should be recognized as a closely interrelated and intricately regulated signaling network.

\subsection{The Possible Mechanisms of Coronavirus-Induced ER Stress Responses}

Increased expression of GRP78, GRP94 and other ER stress related genes has been determined in cells infected with various coronaviruses. These include mouse hepatitis virus (MHV), severe acute respiratory syndrome coronavirus (SARS-CoV) and infectious bronchitis virus (IBV) [18-20]. Activation of ER stress response can be also detected in cell overexpressing the SARS-CoV spike protein [21,22], protein 3a [23], protein 6 [24], protein 8a, and protein 8b [25].

Although not completely illustrated, it is proposed that coronavirus induces ER stress via three potential processes [26]. First, translation, folding and modification of large amounts of coronavirus structural proteins, in particular the heavily N-link glycosylated spike protein, significantly increases the burden of the ER in infected cells. Indeed, overexpression of the spike protein from SARS-CoV [21], MHV [20] or IBV can all activate UPR. Maturation of the spike protein could further exhaust chaperones inside the ER lumen such as calnexin, which is known to physically bind to the SARS-CoV spike protein to facilitate its proper folding [27]. Second, in order to assemble the replication/transcription complex, coronavirus induces the rearrangement of ER membrane into double membrane vesicles (DMVs), zippered ER or ER spherules [28,29]. DMVs formation could be observed in cells overexpressing the SARS-CoV non-structural protein nsp3, nsp4 and nsp6, suggesting their involvement in coronavirus-induced membrane remodeling [30]. Moreover, DMVs formed in cells infected with SARS-CoV are derived from a modified reticulovesicular network connecting to the ER, as determined by high resolution electron tomography [31]. Also, MHV may hijack vesicles originated from the ER and use the membrane for DMV formation [32]. Finally, morphogenesis and budding of mature virus particles deplete the membrane component in the ER. Assembly and budding of coronavirus virions occur in the ER-Golgi intermediate compartment (ERGIC), a membrane system that is structurally and functionally extended from the ER [33,34]. It has been well established that depletion of ER lipid components (such as phosphatidylcholine) alters the morphology of ER and pertubs trafficking of protein cargo in the Golgi [35].

Taken together, current evidence demonstrates that coronavirus infection induces ER stress and triggers UPR in general. It is apparent that coronavirus might subvert or utilize certain aspects of the UPR to benefit its own replication and pathogenesis.

\subsection{Coronavirus-Induced UPR and Its Implication in Pathogenesis}

The IRE1-XBP1 pathway is activated by MHV [36] and IBV infection [37], which may be caused by the accumulation of the spike protein in ER lumen [20]. However, either SARS-CoV infection or SARS-CoV spike protein overexpression does not lead to XBP1 splicing [20], suggesting the modulation of UPR branches differs for different coronaviruses. Interestingly, when the E gene is deleted from the SARS-CoV genome, the resulting mutant virus (rSARS-CoV- $\Delta \mathrm{E}$ ) is significantly attenuated, but significantly activates XBP1 splicingand up-regulates other cellular stress genes, leading to increased apoptosis [38]. The study suggests that SARS-CoV E protein suppresses the IRE1-XBP1 pathway activation and inhibits apoptosis induction, although the mechanism remains unknown.

As for MHV, in spite of the observed XBP1 mRNA splicing, neither the spliced XBP1 protein (XBP1s) nor the upregulation of downstream UPR genes could be detected, presumably resulted from the sustained translational suppression due to eIF2 $\alpha$ phosphorylation [36]. Conversely, significant 
upregulation of UPR genes (such as ERdj4 and p58 ${ }^{\mathrm{IPK}}$ ) can be detected in cells infected with IBV, indicating full activation of the IRE1-XBP1 pathway [37]. Moreover, RNA interference of IRE1 and inhibition of XBP1s drastically potentiate IBV-induced apoptosis, whereas overexpression of IRE1 and XBP1s promotes cell survival, pointing to an anti-apoptotic nature of the IRE1-XBP1 pathway during IBV infection [37]. Activation of a pro-survival response at the late stage of infection could benefit the virus, by giving more time for virus particle assembly and release before the infected cells are disintegrated. However, knockdown of IRE1 does not significantly affect the production of infectious IBV in the supernatant [37]. Therefore, the physiological significance of IRE1 during coronavirus infection needs to be determined with further experiments and with appropriate in vivo models.

Apart from apoptosis, activation of IRE1 may affect other cellular events that modulate the pathogenesis of coronavirus infection. For example, IRE1 can also modulate pro-inflammatory response by activation of nuclear factor kappa-light-chain-enhancer of activated B cells (NF- $\mathrm{kB}$ ) and induction of cytokines such as interleukin 6 (IL-6) and IL-8 [39,40]. On the other hand, XBP1 has been demonstrated to directly or indirectly modulate the expression of various cytokines and type-I interferons (IFNs) [41-43]. Unpublished data from this group have also implicated the involvement of IRE1 and XBP1 in the transcription of IL- 8 and IFN- $\beta$ during IBV infection. Further investigation needs to be carried out for other coronaviruses to understand the detailed mechanisms and potential counter measures implemented by coronaviruses.

Whether or not coronavirus activates the ATF6 branch of UPR during coronavirus infection has not been fully investigated. Proteolytic cleavage of ATF6 into its active form cannot be detected in cells infected with SARS-CoV [38]. Similarly, ATF6 reporter constructs co-transfected with the SARS-CoV spike protein showed minimal reporter production [21]. In contrast, ATF6 cleavage is observed by MHV infection, although both the full-length and the cleaved form of ATF6 decreased significantly at late stage of infection due to sustained translational attenuation [36]. Subsequently, neither the induction of downstream UPR genes nor the activation of the ERSE reporter construct could be detected. Interestingly, the SARS-CoV 8ab protein binds to ATF6 in vitro and promotes its cleavage in the co-transfected cells [25]. However, further experiments using recombinant viruses are required.

Coronavirus also manipulate PERK activity and the level of phosphor-eIF $2 \alpha$ to control protein synthesis, such as IBV [18,44], MHV [45], SARS-CoV [23,46,47]. The regulation of PERK-eIF2 $\alpha$ pathway by various coronaviruses will be discussed in detail in Section 3. The regulation of ER stress response pathways by coronavirus is summarized in Figure 1.

\section{Activation and subversion of p38 and JNK signaling pathways by coronavirus infection}

\subsection{The Signaling Pathways of Stress-Activated Protein Kinase p38 and JNK}

The mitogen activated (MAP) kinases are evolutionarily conserved protein kinases that regulate a diversity of critical cellular signaling pathways, such as cell division, differentiation, autophagy, apoptosis, innate immunity and pro-inflammatory response [48]. So far, four subgroups of MAP kinases have been identified in metazoans, namely the extracellular regulated kinase $1 / 2$ (ERK1/2), ERK5, the p38 MAP kinase and the c-Jun N-terminal kinases (JNK) [49,50]. Among them, the ERK1/2 signaling is triggered by growth factors and mitogens, whereas the p38 and JNK are mainly responsive to cellular stress, such as DNA damage, ionizing radiation and protein synthesis inhibition [49].

MAP kinases are phosphorylated by the upstream MAP kinase kinases (MAPKKs), which are in turn phosphorylated by upstream kinases in response to different cellular or environmental stimulations [51]. In particular, p38 is activated by MKK3, MKK4 [52] or MKK6 [53], whereas JNK can be phosphorylated by MKK4 or MKK7 [54]. Dual phosphorylation of Thr and Tyr residues in the conserved TxY motif (Thr-Gly-Tyr for p38 and Thr-Pro-Tyr for JNK) is essential for the complete activation of MAP kinases [49]. 
Upon activation, p38 translocates into the nucleus and activates multiple effector proteins, such as MAPK-Activated Protein Kinase-2 (MAPKAPK2), which in turn activates critical transcription factors such as cAMP Response Element-Binding protein (CREB) and Activating Transcription Factor 1 (ATF1) [55]. Moreover, p38 can also directly phosphorylate other important transcription factors such as $\mathrm{p} 53$ and $\mathrm{CHOP}[56,57]$.

As for JNK, activated JNK phosphorylates c-Jun and other downstream substrates, enhancing their transcription activity [58]. Activated c-Jun dimerizes with other proteins such as cellular FBJ murine osteosarcoma (c-Fos) to form the activator protein 1 complex, thereby inducing genes harboring the 12-O-tetradecanoylphorbol-13-acetate (TPA) response element [59].

\subsection{Induction and Subversion of the p38 Pathway by Coronavirus Infection}

Phosphorylation of $\mathrm{p} 38$ is detected in cells infected with several coronaviruses including MHV [60], SARS-CoV [61], feline coronavirus (FCoV) [62], IBV [63] and transmissible gastroenteritis coronavirus (TGEV) [64]. Moreover, the p38 pathway is also activated in cells overexpressing the SARS-CoV accessory protein 3a [65] and 7a [66], although the physiological significance during an actual infection has not been fully examined. Coronavirus-induced p38 activation is likely mediated by the upstream kinase MKK3/6, which is phosphorylated in cells infected with MHV [67] and IBV [63].

Multiple reports have suggested the critical role of p38 in the inflammatory process during coronavirus infection. For example, inhibition of p38 significantly reduces the transcription and secretion of IL-6 in MHV-infected cells [67]. Similarly, the induction of IL-6 and IL-8 is dependent on p38 activation in IBV-infected cells [63]. Moreover, production of tumor necrosis factor alpha (TNF- $\alpha$ ) and IL-1 $\beta$ in FIPV-infected cells is significantly inhibited by p38 inhibitor [62]. Finally, p38 has been demonstrated to induce the expression of macrophage prothrombinase fibrinogen-like protein 2 (Fgl2), a protein crucial for the pathogenesis of fulminant hepatitis in MHV-3-infected mice [60,68].

Notably, coronaviruses have developed various mechanisms to subvert the activation of the p38 pathway. For instance, IBV has been shown to induce the transcription of dual-specificity phosphatase 1 (DUSP1), which can dephosphorylate the active p38 and suppress the production of excessive pro-inflammatory cytokines [63]. In contrast, the SARS-CoV E protein seems to activate p38 and induces inflammation [69]. Specifically, the PDZ-binding motif (PBM) in the SARS-CoV $\mathrm{E}$ protein can interact with the cellular protein syntenin, resulting in its redistribution from the nucleus to the cytoplasm and activation of the p38 pathway [69]. In fact, production of inflammatory cytokines is significantly reduced in syntenin-knockdown cells, or in mice infected with PBM-deleted E recombinant virus compared with mice infected with the wild type virus [69]. Therefore, different coronaviruses may use distinct mechanisms to modulate the p38 pathway, so as to establish the cellular environment suitable for viral replication and spreading.

\subsection{Activation of JNK during Coronavirus Infection}

Compared with p38, coronavirus-induced activation of the JNK pathway has been less well characterized. JNK phosphorylation has been determined in cells infected with MHV [67], SARS-CoV [67] and IBV [37]. Activation of the JNK pathway has also been demonstrated in cells overexpressing the $\mathrm{N}$ protein, accessory protein $3 \mathrm{a}, 3 \mathrm{~b}$ or $7 \mathrm{a}$ of SARS-CoV [70-72].

In a study using specific inhibitors, Mizutani et al have shown that persistent SARS-CoV infection requires the intact signaling of JNK and Akt in Vero E6 cells, suggesting a pro-survival function for these kinases [73]. Phosphorylation of JNK and Akt is likely induced by the SARS-CoV N protein, and the anti-apoptotic Bcl2 and Bcl-xL proteins may also contribute to the persistent infection [74]. In contrast, JNK signaling has been found to facilitate apoptotic cell death in IBV-infected cells [37]. Therefore, it is possible that JNK serves different functions in cells infected with different coronaviruses, and presumably at different stages of infection.

In terms of its involvement in proinflammatory response, induction of TNF- $\alpha$ and IL- 6 by MHV-A59 infection in primary mouse astrocytes depends on JNK, but not NF- $\mathrm{kB}$ or other MAP 
kinases [75]. The SARS-CoV spike protein also activates the protein kinase $C$ epsilon, which induces JNK phosphorylation in a calcium-independent manner. Moreover, induction of IL-8, activation of CREB and the transcription of cyclooxygenase-2 (COX-2) gene in cells transfected with SARS-CoV spike also requires JNK [76,77].

The modulation of MAPK pathways by coronavirus is summarized in Figure 2.

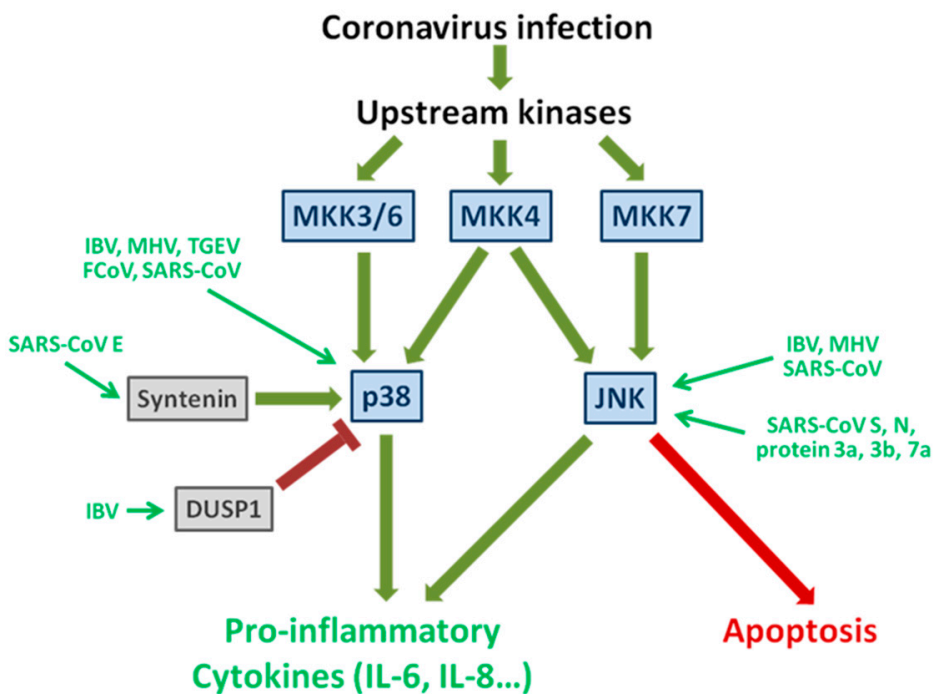

Figure 2. Activation and subversion of p38 and JNK signaling pathways by coronavirus infection. Coronavirus infection activates upstream kinases, which in turns activate MKK3/6, MKK4 and MKK7. JNK is phosphorylated by MKK4 and/or MKK7, while p38 is activated by MKK3/6 and/or MKK4. Both p38 and JNK have been shown to modulate inflammatory response by regulating the production of pro-inflammatory cytokines (such as IL-6, IL-8 and TNF- $\alpha$ ). JNK has also been implicated in the induction of apoptosis in coronavirus-infected cells. The known coronaviruses and viral proteins modulating p38 and JNK signaling are also indicated. Green arrows are activating and red blunt arrows are inhibiting. See text for detail.

\section{Translational Control by Coronavirus and Its Implication in Pathogenesis}

\subsection{Viral Protein Translation of Coronavirus}

Coronavirus replicate entirely within the cytoplasm of their host cells, where they produced five to nine genomic mRNAs [41]. All mRNAs contain a common 5'-leader sequence (65-90 nucleotides long) and a co-terminal $3^{\prime}$-end [78]. The $5^{\prime}$-leader sequence binds to $\mathrm{N}$ protein and form a complex, may act as a strong translation initiation signal and promote viral mRNA translation $[79,80]$. For each mRNA, only the $5^{\prime}$-open reading frames (ORFs) are translated via cap-dependent manner. Most of the mRNAs are monocistronic, while some mRNAs are bicistronic or tricistronic. mRNA1 encodes two large precursor polyproteins ppla and pplab, pplab is translated via -1 programmed ribosomal shifting manner. Both polyproteins ppla and pplab are proteolytically cleaved by virus encoded proteases, papain-like proteinase $\left(\mathrm{PL}^{\mathrm{pro}}\right)$ and $3 \mathrm{C}$-like proteinase ( $3 \mathrm{CL}^{\mathrm{pro}}$ ), into 13-16 mature non-structural proteins (nsps). Many of the nsps participate in viral RNA replication and transcription. The subgenomic mRNAs are translated into structural proteins haemagglutinin-esterase (HE), spike protein (S), envelope protein (E), membrane protein $(\mathrm{M})$, nucleocapsid protein $(\mathrm{N})$, and several nsps, respectively. HE is only encoded by $\beta$ coronavirus. The expression ratio of these genes is regulated at the level of transcription, during which time the shorter mRNAs are produced more abundantly than the longer one [81,82]. The $5^{\prime}$-UTR (untranslated region), which is unique for each of mRNA, also regulate the rate of each mRNA translation [83]. 
Viruses utilize host translation machinery to finish viral protein translation. In response to acute viral infection, host cell would shut down protein translation system to cope with the infection stress, which is regarded as integrated stress response. Integrated stress response is marked by phosphorylation of eIF $2 \alpha$, down regulation of the general cap-dependent protein synthesis, and up-regulation of the expression of certain transcription factors, such as ATF4. To acquire successful production of viral proteins, viruses must overcome this obstacle to ensure viral protein synthesis. The translation regulation by virus infection occurs by a number of ways, such as degradation of cellular mRNAs, alteration the activity of ribosome and associated factors, competitive displacement of cellular mRNAs by viral mRNAs for translation, etc. Coronavirus mRNAs are $5^{\prime}$-capped and $3^{\prime}$-polyadenylated, structurally equivalent to host mRNAs. Due to the translation competition between cellular and viral mRNAs for limiting number of ribosomes and associated factors, coronavirus must hijack the host translational machinery to produce their own proteins. More and more studies focus the mechanisms of translational control by coronavirus. SARS-CoV [84-87], MERS-coronavirus [88], MHV [36,89,90], transmissible gastroenteritis virus (TEGV) [91,92], porcine epidemic diarrhea virus (PEDV) [93], bat coronaviruses [94], have been shown to induce host translation shutoff in susceptible cells. In the other way, infectious bronchitis virus (IBV) maintains protein translation in infected cells [44]. The mechanisms of coronavirus modulated translation will be summarized in following sections.

\subsection{Regulation of Host Protein Synthesis via Targeting to eIF2 $\alpha$}

Host protein translation shutoff is not only due to the host mRNA degradation and specific viral protein induced ribosome disfunction, but also induced by virus infection stress stimuli [95]. The infection stress stimili induces translational shut off via the phosphorylation of eukaryotic initiation factor $\alpha(\mathrm{eIF} 2 \alpha)$. eIF $2 \alpha$, together with eIF2 $\beta$, and eIF2 $\gamma$, forms eIF2, mediates the binding of initiator Met-tRNAi to the ribosome in a GTP-dependent manner. Once the initiation is completed, eIF2-GDP is released from the ribosome, and GDP is exchanged for GTP to form active eIF2-GTP, participating in another round of translation initiation. eIF2 is inactivated by phosphorylation of eIF2 $\alpha$ on Ser51, which has increased affinity to eIF2 $\beta$ and blocks the exchange of GDP to GTP, thus depleting the active eIF2 $\beta$-GTP pool. Since the cellular concentration of eIF2 $\beta$ is much lower than eIF $2 \alpha$, a small proportion of phosphor-eIF2 $\alpha$ can exhaust eIF2 $\beta$ by sequestration [96]. Therefore, phosphorylation of eIF2 $\alpha$ is a checkpoint of protein synthesis initiation and relieves stress through ceasing translation under infection stress. Given the importance of eIF $2 \alpha$ in translation initiation, the level of phosphor-eIF $2 \alpha$ is no wonder regulated under infection stress. There are four eIF2 $\alpha$ kinases, GCN2, HRI, PERK, and PKR. These kinases are activated as a result of discrete stress, such as amino acid starvation or ultraviolet light (GCN2), heme deficiency (HRI), excess unfolded proteins accumulated in the ER [97], and double-stranded RNA (dsRNA) produced in virus-infected cells (PKR) [98].

Under virus infection stress, PKR is induced as an IFN stimulated gene (ISG) and activated by dsRNA produced during the course of viral infection. dsRNA binds to PKR and causes a conformational change, leading to the dimerization and autophosphorylation of this kinase [99]. PKR phosphorylates eIF2 $\alpha$ and inhibits protein synthesis, thereby rendering an antiviral effect [96]. PERK, another eIF2 $\alpha$ kinase, usually activated by excess viral proteins loaded in the ER $[2,100]$. PKR and PERK activation inhibits protein synthesis globally and curtails viral spread through inactivating eIF2 $\alpha$ making these two kinases key players in integrated stress response to virus infection. High level of phosphor-eIF $2 \alpha$ leads to preferential translation of transcription factor ATF4, which promotes a number of genes expression. One of ATF4 target genes is growth arrest and DNA damage-inducible protein 34 (GADD34), a regulatory subunit of protein phosphatase 1 (PP1). GADD34 helps PP1 to dephosphorylate eIF2 $\alpha$, thereby recovering global protein synthesis. The induction of GADD34 is a canonical cellular response to counteract PERK/PKR via preserving eIF2 $\alpha$ activity $[5,101]$. A number of viruses encode viral protein mimicing the function of GADD34, helps PP1 to counterbalance the PKR/PERK-mediated phosphorylation of eIF $2 \alpha$. 
Regarding to coronavirus, it was reported that SARS-CoV infection activates PERK by phosphorylation, leading to sustained phosphorylation of eIF2 $\alpha$ in 293T/ACE2 cells. The SARS-CoV infection also activates PKR. Unexpectedly, the activation of PKR is not involved in eIF2 $\alpha$ phosphorylation and virus replication, but plays a role in viral induced apoptosis [47]. Overexpresson of SARS-CoV spike glycoprotein resulted in activation of PERK and upregulation of GRP78/GRP94 [46]. Another ER localized transmembrane glycoprotein, 3a, also activates PERK and thus increases the level of phosphor-eIF2 $\alpha$, leading to activation of GRP78, GRP94, ATF4, and CHOP promoter, which is demonstrated by co-transfection of luciferase reporter plasmid with plasmid encoding 3a [23]. It is unclear whether spike protein or 3a protein plays a major role in SARS-CoV induced translation shutoff, as the translational rate is not examined upon overexpression of these proteins.

MHV strain A59 infection increases the level of phosphor-eIF2 $\alpha$ and attenuates the host protein synthesis, resulting in preferential translation of ATF4. Unexpectedly, the ATF4 target genes, GADD34 and $\mathrm{CHOP}$, are not detected during MHV infection, which may correlates with the persistent phosphorylation of eIF2 $\alpha$ and sustained suppression of host protein synthesis [36,45]. The MHV induced translation inhibition coincides with degradation of host mRNA. The formation of stress granules and $\mathrm{P}$ bodies, the sites of mRNA stalling and degradation respectively, are detected in MHV-infected LR7 cells [102]. MHV infection also leads to RNase L-independent specific 28S rRNA cleavage in all susceptible cell lines, which may contribute to MHV induced translational inhibition [103]. Although MHV infection induces protein synthesis inhibition, the viral proteins are still efficiently made, which can be attributed to the $5^{\prime}$-leader sequence and $\mathrm{N}$ protein in viral mRNA or the abundance of viral mRNA. MHV replication is not negatively affected either in the host translational shutoff-deficient (eIF2 $\alpha$ S51A) MEF cells or stress granule impaired (TIA-1 ${ }^{-/-}$ and $\mathrm{TIAR}^{-/-}$) MEFs, suggesting the translational inhibition is not beneficial for virus replication in vitro [102].

To allow adequate proteins synthesis, some coronaviruses harness strategies to prevent eIF2 $\alpha$ phosphorylation. For example, IBV activates PKR and PERK at early infection times, leading to phosphorylation of eIF2 $\alpha$, however, the activation of PKR and PERK is suppressed at late infection times by unknown mechanisms Furthermore, IBV infection up-regulates GADD34 expression, which is a regulatory subunit of PP1. By suppression of kinase PERK and PKR activity, and enhancement of phosphotase GADD34-PP1 activity, phosphor-eIF2 $\alpha$ was reduced to low level at late infection times, resulting in robust protein synthesis throughout the infection course. The sustained protein translation is beneficial for virus replication, which is verified by overexpression of GADD34 [18,44]. Unlike IBV, which maintains protein synthesis via blockage of PKR/PERK activity and up-regulation of GADD34, TEGV infection leads to PKR activation with a maximum at 12 h.p.i.. However, the level of phosphor-eIF2 $\alpha$ in TEGV infected cell is comparable to mock-infected cells, and moderate protein synthesis is observed throughout the infection times. A genus-specific protein 7 mimicking the function of GADD34 is identified in TEGV, with a conserved sequence motif (RVIFLVL) binding to PP1c. The interaction of protein 7 and pp1c is required for dephosphorylation of eIF2 $\alpha$, inhibition of cellular RNA degradation, and maintenance of protein synthesis. Infect cells with TGEV $\Delta 7$ (with deletion of protein 7) results in impaired protein synthesis, faster and stronger $28 \mathrm{~S}$ rRNA degradation, and increased apoptosis, compared to that in wild type TEGV infected cells. Moreover, TGEV $\Delta 7$ infected piglets exhibits accelerated pathology and more lesions at 4 dpi when compared with the wild type TGEV infected one. Piglets infected with virulent enteric strain TGEV-SC11- $\Delta 7$ develop faster and more pronounced clinical disease. Thus, TGEV protein 7 functions to relieve the integrated stress response and to recover protein synthesis, thereby attenuating virus virulence [104].

\subsection{Suppression of Host Protein Synthesis and IFN Response by Coronavirus nsp1}

Coronavirus nsp1, the most $\mathrm{N}$-terminal product of the pp1a polyprotein, is only encoded by two genera, $\alpha$ and $\beta$ coronavirus. This protein is highly divergent among coronaviruses and functions to regulate host and viral gene expression. Recently, a number of reports demonstratethat nsp1 is 
involved in the regulation of host protein translation. Among $\beta$ coronavirus, SARS-CoV nsp1 was first identified to block the expression of reporter gene under the control constitutive promoters [84]. This protein associates and inactivates the $40 \mathrm{~S}$ ribosomal subunit, thus preventing viral and cellular mRNA translation [105]. Moreover, the Nsp1-40S ribosome complex also promotes cellular mRNA degradation via inducing an endonucleolytic mRNA cleavage in the $5^{\prime}$ region of the capped mRNA $[84,105,106]$. The presence of $5^{\prime}$-end leader sequence in viral mRNA, and the binding of stem loop 1 in the $5^{\prime}$-UTR with nsp1, protect viral mRNAs from nsp1-induced RNA cleavage, and facilitate efficient viral gene expression in infected cells $[87,106]$. In vivo studies suggested that SARS-CoV nsp1 counteracts the host innate immune response via suppression of host gene expression, including type I IFN, thereby playing a crucial role in virus virulence $[85,105,107]$. The inhibition of host protein synthesis and IFN inhibition by nsp1 seems to be a general phenomenon in coronavirus, which is also observed in other coronaviruses. For example, the nsp1 of bat coronavirus strains, Rm1, 133 and HKU9-1, exhibit functional similarities with SARS-CoV nsp1, with the ability to prevent host protein synthesis and suppress innate immune functions [94,108]. MERS-coronavirus nsp1 also negatively regulate host gene expression by inducing the degradation and inhibiting the translation of host mRNA. This protein selectively targets nuclear host mRNA and transports them to the cytoplasm for degradation and translation inhibition [88]. MHV nsp1 displays similar function to suppress the expression of reporter genes and host genes [108]. Deletion or mutation of potential functional domain of nsp1 severely attenuates $\mathrm{MHV}$, and influences hepatotropism and liver pathogenesis in vivo, and elicits potent immune response. Thus, nsp1 is a major virulence factor [108-110].

Among $\alpha$ coronavirus, TEGV nsp1 suppresses host mRNAs translation without affecting their stability. This protein also inhibits the translation of different reporter mRNAs in cells or cell extract, but not in the in vitro translation system such as rabbit reticulocyte lysate, indicating that TEGV nsp1 relies on host factors to exert the inhibitory effect [91]. HCoV-229E and HCoV-NL63 nsp1 inhibit the expression of reporter genes, probably via binding to ribosomal protein $\mathrm{S} 6$ and blocking the mRNA binding to the $40 S$ ribosomal subunit $[108,111]$. The essential role of covonavirus nsp1 in regulation of protein synthesis and IFN response, makes it a virulence factor and was targeted to developed live attenuated coronavirus vaccine $[85,107,110]$.

\section{Conclusions}

Replication of coronavirus induces UPR and other cellular stress responses in the infected cells, triggering innate immunity and antiviral signaling pathways. The translational control constitutes one aspect of cellular antiviral response, and it is targeted and subverted by various coronaviruses at different levels via different mechanisms. It is hoped that further studies on these subjects will promote a more complete understanding of corovirus-host interactions and shed light on the development of antiviral therapeutics.

Acknowledgments: This work was supported by Academic Research Fund (AcRF) Tier 1 grant (RGT17/13), Singapore, Nanyang Technological University and Ministry of Education, Singapore, Ministry of Education AcRF Tier 2 grant (ACR47/14), Singapore, and Shanghai Natural Science Foundation (15ZR1149600), China. The costs of this publication in open access was covered by Elite Youth program of Chinese Academy of Agricultural Sciences, China

Conflicts of Interest: The authors declare no conflict of interest. The founding sponsors had no role in the design of the study; in the collection, analyses, or interpretation of data; in the writing of the manuscript, and in the decision to publish the results.

\section{References}

1. Ron, D.; Walter, P. Signal integration in the endoplasmic reticulum unfolded protein response. Nat. Rev. Mol. Cell Biol. 2007, 8, 519-529. [CrossRef] [PubMed]

2. Shi, Y.; Vattem, K.M.; Sood, R.; An, J.; Liang, J.; Stramm, L.; Wek, R.C. Identification and characterization of pancreatic eukaryotic initiation factor $2 \alpha$-subunit kinase, PEK, involved in translational control. Mol. Cell. Biol. 1998, 18, 7499-7509. [CrossRef] [PubMed] 
3. Harding, H.P.; Zhang, Y.; Ron, D. Protein translation and folding are coupled by an endoplasmic-reticulumresident kinase. Nature 1999, 397, 271-274. [PubMed]

4. Harding, H.P.; Novoa, I.; Zhang, Y.; Zeng, H.; Wek, R.; Schapira, M.; Ron, D. Regulated translation initiation controls stress-induced gene expression in mammalian cells. Mol. Cell 2000, 6, 1099-1108. [CrossRef]

5. Brush, M.H.; Weiser, D.C.; Shenolikar, S. Growth arrest and DNA damage-inducible protein GADD34 targets protein phosphatase $1 \alpha$ to the endoplasmic reticulum and promotes dephosphorylation of the $\alpha$ subunit of eukaryotic translation initiation factor 2. Mol. Cell. Biol. 2003, 23, 1292-1303. [CrossRef] [PubMed]

6. Yoshida, H.; Matsui, T.; Yamamoto, A.; Okada, T.; Mori, K. XBP1 mRNA is induced by ATF6 and spliced by IRE1 in response to ER stress to produce a highly active transcription factor. Cell 2001, 107, 881-891. [CrossRef]

7. Hollien, J.; Lin, J.H.; Li, H.; Stevens, N.; Walter, P.; Weissman, J.S. Regulated IRE1-dependent decay of messenger RNAs in mammalian cells. J. Cell Biol. 2009, 186, 323-331. [CrossRef] [PubMed]

8. Urano, F.; Wang, X.; Bertolotti, A.; Zhang, Y.; Chung, P.; Harding, H.P.; Ron, D. Coupling of stress in the ER to activation of JNK protein kinases by transmembrane protein kinase IRE1. Science 2000, 287, 664-666. [CrossRef] [PubMed]

9. Yoneda, T.; Imaizumi, K.; Oono, K.; Yui, D.; Gomi, F.; Katayama, T.; Tohyama, M. Activation of caspase-12, an endoplastic reticulum (ER) resident caspase, through tumor necrosis factor receptor-associated factor 2-dependent mechanism in response to the ER stress. J. Biol. Chem. 2001, 276, 13935-13940. [PubMed]

10. Ye, J.; Rawson, R.B.; Komuro, R.; Chen, X.; Dave, U.P.; Prywes, R.; Brown, M.S.; Goldstein, J.L. ER stress induces cleavage of membrane-bound ATF6 by the same proteases that process SREBPs. Mol. Cell 2000, 6, 1355-1364. [CrossRef]

11. Adachi, Y.; Yamamoto, K.; Okada, T.; Yoshida, H.; Harada, A.; Mori, K. ATF6 is a transcription factor specializing in the regulation of quality control proteins in the endoplasmic reticulum. Cell Struct. Funct. 2008, 33, 75-89. [CrossRef] [PubMed]

12. Calfon, M.; Zeng, H.; Urano, F.; Till, J.H.; Hubbard, S.R.; Harding, H.P.; Clark, S.G.; Ron, D. IRE1 couples endoplasmic reticulum load to secretory capacity by processing the XBP-1 mRNA. Nature 2002, 415, 92-96. [CrossRef] [PubMed]

13. Lee, T.G.; Tang, N.; Thompson, S.; Miller, J.; Katze, M.G. The 58,000-dalton cellular inhibitor of the interferon-induced double-stranded RNA-activated protein kinase (PKR) is a member of the tetratricopeptide repeat family of proteins. Mol. Cell. Biol. 1994, 14, 2331-2342. [CrossRef] [PubMed]

14. Yan, W.; Frank, C.L.; Korth, M.J.; Sopher, B.L.; Novoa, I.; Ron, D.; Katze, M.G. Control of PERK eIF2 $\alpha$ kinase activity by the endoplasmic reticulum stress-induced molecular chaperone P58IPK. Proc. Natl. Acad. Sci. USA 2002, 99, 15920-15925. [CrossRef] [PubMed]

15. Eletto, D.; Dersh, D.; Gidalevitz, T.; Argon, Y. Protein disulfide isomerase A 6 controls the decay of IRE1 $\alpha$ signaling via disulfide-dependent association. Mol. Cell 2014, 53, 562-576. [CrossRef] [PubMed]

16. Teske, B.F.; Wek, S.A.; Bunpo, P.; Cundiff, J.K.; McClintick, J.N.; Anthony, T.G.; Wek, R.C. The eIF2 kinase PERK and the integrated stress response facilitate activation of ATF6 during endoplasmic reticulum stress. Mol. Biol. Cell 2011, 22, 4390-4405. [CrossRef] [PubMed]

17. Vekich, J.A.; Belmont, P.J.; Thuerauf, D.J.; Glembotski, C.C. Protein disulfide isomerase-associated 6 is an ATF6-inducible ER stress response protein that protects cardiac myocytes from ischemia/ reperfusion-mediated cell death. J. Mol. Cell. Cardiol. 2012, 53, 259-267. [CrossRef] [PubMed]

18. Liao, Y.; Fung, T.S.; Huang, M.; Fang, S.G.; Zhong, Y.; Liu, D.X. Upregulation of CHOP/GADD153 during coronavirus infectious bronchitis virus infection modulates apoptosis by restricting activation of the extracellular signal-regulated kinase pathway. J. Virol. 2013, 87, 8124-8134. [CrossRef] [PubMed] 
19. Tang, B.S.F.; Chan, K.-H.; Cheng, V.C.C.; Woo, P.C.Y.; Lau, S.K.P.; Lam, C.C.K.; Chan, T.-L.; Wu, A.K.L.; Hung, I.F.N.; Leung, S.-Y.; et al. Comparative host gene transcription by microarray analysis early after infection of the Huh7 cell line by severe acute respiratory syndrome coronavirus and human coronavirus 229E. J. Virol. 2005, 79, 6180-6193. [CrossRef] [PubMed]

20. Versteeg, G.A.; van de Nes, P.S.; Bredenbeek, P.J.; Spaan, W.J.M. The coronavirus spike protein induces endoplasmic reticulum stress and upregulation of intracellular chemokine mRNA concentrations. J. Virol. 2007, 81, 10981-10990. [CrossRef] [PubMed]

21. Chan, C.-P.; Siu, K.-L.; Chin, K.-T.; Yuen, K.-Y.; Zheng, B.; Jin, D.-Y. Modulation of the unfolded protein response by the severe acute respiratory syndrome coronavirus spike protein. J. Virol. 2006, 80, 9279-9287. [CrossRef] [PubMed]

22. Yeung, Y.-S.; Yip, C.-W.; Hon, C.-C.; Chow, K.Y.C.; Ma, I.C.M.; Zeng, F.; Leung, F.C.C. Transcriptional profiling of Vero E6 cells over-expressing SARS-CoV S2 subunit: Insights on viral regulation of apoptosis and proliferation. Virology 2008, 371, 32-43. [CrossRef] [PubMed]

23. Minakshi, R.; Padhan, K.; Rani, M.; Khan, N.; Ahmad, F.; Jameel, S. The SARS coronavirus 3a protein causes endoplasmic reticulum stress and induces ligand-independent downregulation of the type 1 interferon receptor. PLoS ONE 2009, 4, e8342. [CrossRef] [PubMed]

24. Ye, Z.; Wong, C.K.; Li, P.; Xie, Y. A SARS-CoV protein, ORF-6, induces caspase-3 mediated, ER stress and JNK-dependent apoptosis. Biochim. Biophys. Acta 2008, 1780, 1383-1387. [CrossRef] [PubMed]

25. Sung, S.-C.; Chao, C.-Y.; Jeng, K.-S.; Yang, J.-Y.; Lai, M.M.C. The 8ab protein of SARS-CoV is a luminal ER membrane-associated protein and induces the activation of ATF6. Virology 2009, 387, 402-413. [CrossRef] [PubMed]

26. Fung, T.S.; Huang, M.; Liu, D.X. Coronavirus-induced ER stress response and its involvement in regulation of coronavirus-host interactions. Virus Res. 2014, 194, 110-123. [CrossRef] [PubMed]

27. Fukushi, M.; Yoshinaka, Y.; Matsuoka, Y.; Hatakeyama, S.; Ishizaka, Y.; Kirikae, T.; Sasazuki, T.; Miyoshi-Akiyama, T. Monitoring of $S$ protein maturation in the endoplasmic reticulum by calnexin is important for the infectivity of severe acute respiratory syndrome coronavirus. J. Virol. 2012, 86, 11745-11753. [CrossRef] [PubMed]

28. David-Ferreira, J.F.; Manaker, R.A. An electron microscope study of the development of a mouse hepatitis virus in tissue culture cells. J. Cell Biol. 1965, 24, 57-78. [CrossRef] [PubMed]

29. Maier, H.J.; Hawes, P.C.; Cottam, E.M.; Mantell, J.; Verkade, P.; Monaghan, P.; Wileman, T.; Britton, P. Infectious bronchitis virus generates spherules from zippered endoplasmic reticulum membranes. $m B i o$ 2013, 4. [CrossRef] [PubMed]

30. Angelini, M.M.; Akhlaghpour, M.; Neuman, B.W.; Buchmeier, M.J. Severe acute respiratory syndrome coronavirus nonstructural proteins 3, 4, and 6 induce double-membrane vesicles. mBio 2013, 4. [CrossRef] [PubMed]

31. Knoops, K.; Kikkert, M.; van de Worm, S.H.E.; Zevenhoven-Dobbe, J.C.; van der Meer, Y.; Koster, A.J.; Mommaas, A.M.; Snijder, E.J. SARS-CoV replication is supported by a reticulovesicular network of modified endoplasmic reticulum. PLoS Biol. 2008, 6. [CrossRef] [PubMed]

32. Reggiori, F.; Monastyrska, I.; Verheije, M.H.; Calì, T.; Ulasli, M.; Bianchi, S.; Bernasconi, R.; de Haan, C.A.M.; Molinari, M. Coronaviruses Hijack the LC3-I-positive EDEMosomes, ER-derived vesicles exporting short-lived ERAD regulators, for replication. Cell Host Microbe 2010, 7, 500-508. [CrossRef] [PubMed]

33. Klumperman, J.; Locker, J.K.; Meijer, A.; Horzinek, M.C.; Geuze, H.J.; Rottier, P.J. Coronavirus M proteins accumulate in the Golgi complex beyond the site of virion budding. J. Virol. 1994, 68, 6523-6534. [PubMed]

34. Stertz, S.; Reichelt, M.; Spiegel, M.; Kuri, T.; Martínez-Sobrido, L.; García-Sastre, A.; Weber, F.; Kochs, G. The intracellular sites of early replication and budding of SARS-CoV. Virology 2007, 361, 304-315. [CrossRef] [PubMed]

35. Testerink, N.; van de Sanden, M.H.M.; Houweling, M.; Helms, J.B.; Vaandrager, A.B. Depletion of phosphatidylcholine affects endoplasmic reticulum morphology and protein traffic at the Golgi complex. J. Lipid Res. 2009, 50, 2182-2192. [CrossRef] [PubMed]

36. Bechill, J.; Chen, Z.; Brewer, J.W.; Baker, S.C. Coronavirus infection modulates the unfolded protein response and mediates sustained translational repression. J. Virol. 2008, 82, 4492-4501. [CrossRef] [PubMed]

37. Fung, T.S.; Liao, Y.; Liu, D.X. The endoplasmic reticulum stress sensor IRE1 $\alpha$ protects cells from apoptosis induced by the coronavirus infectious bronchitis virus. J. Virol. 2014, 88, 12752-12764. [CrossRef] [PubMed] 
38. DeDiego, M.L.; Nieto-Torres, J.L.; Jiménez-Guardeño, J.M.; Regla-Nava, J.A.; Álvarez, E.; Oliveros, J.C.; Zhao, J.; Fett, C.; Perlman, S.; Enjuanes, L. Severe acute respiratory syndrome coronavirus envelope protein regulates cell stress response and apoptosis. PLoS Pathog. 2011, 7, e1002315. [CrossRef] [PubMed]

39. Cho, J.A.; Lee, A.-H.; Platzer, B.; Cross, B.C.S.; Gardner, B.M.; de Luca, H.; Luong, P.; Harding, H.P.; Glimcher, L.H.; Walter, P.; et al. The unfolded protein response element IRE1 $\alpha$ senses bacterial proteins invading the ER to activate RIG-I and innate immune signaling. Cell Host Microbe 2013, 13, 558-569. [CrossRef] [PubMed]

40. Tam, A.B.; Mercado, E.L.; Hoffmann, A.; Niwa, M. ER stress activates NF- $\kappa$ B by integrating functions of basal IKK activity, IRE1 and PERK. PLoS ONE 2012, 7, e45078. [CrossRef] [PubMed]

41. Hu, F.; Yu, X.; Wang, H.; Zuo, D.; Guo, C.; Yi, H.; Tirosh, B.; Subjeck, J.R.; Qiu, X.; Wang, X.-Y. ER stress and its regulator $X$-box-binding protein-1 enhance polyIC-induced innate immune response in dendritic cells. Eur. J. Immunol. 2011, 41, 1086-1097. [CrossRef] [PubMed]

42. Martinon, F.; Chen, X.; Lee, A.-H.; Glimcher, L.H. TLR activation of the transcription factor XBP1 regulates innate immune responses in macrophages. Nat. Immunol. 2010, 11, 411-418. [CrossRef] [PubMed]

43. Zeng, L.; Liu, Y.-P.; Sha, H.; Chen, H.; Qi, L.; Smith, J.A. XBP-1 couples endoplasmic reticulum stress to augmented IFN- $\beta$ induction via a cis-acting enhancer in macrophages. J. Immunol. 2010, 185, 2324-2330. [CrossRef] [PubMed]

44. Wang, X.; Liao, Y.; Yap, P.L.; Png, K.J.; Tam, J.P.; Liu, D.X. Inhibition of protein kinase R activation and upregulation of GADD34 expression play a synergistic role in facilitating coronavirus replication by maintaining de novo protein synthesis in virus-infected cells. J. Virol. 2009, 83, 12462-12472. [CrossRef] [PubMed]

45. Ye, Y.; Hauns, K.; Langland, J.O.; Jacobs, B.L.; Hogue, B.G. Mouse hepatitis coronavirus A59 nucleocapsid protein is a type I interferon antagonist. J. Virol. 2007, 81, 2554-2563. [CrossRef] [PubMed]

46. Chan, C.P.; Siu, K.L.; Chin, K.T.; Yuen, K.Y.; Zheng, B.; Jin, D.Y. Modulation of the unfolded protein response by the severe acute respiratory syndrome coronavirus spike protein. J. Virol. 2006, 80, 9279-9287. [CrossRef] [PubMed]

47. Krahling, V.; Stein, D.A.; Spiegel, M.; Weber, F.; Muhlberger, E. Severe acute respiratory syndrome coronavirus triggers apoptosis via protein kinase $\mathrm{R}$ but is resistant to its antiviral activity. J. Virol. 2009, 83, 2298-2309. [CrossRef] [PubMed]

48. Keshet, Y.; Seger, R. The MAP kinase signaling cascades: A system of hundreds of components regulates a diverse array of physiological functions. Methods Mol. Biol. 2010, 661, 3-38. [PubMed]

49. Kyriakis, J.M.; Avruch, J. Mammalian mitogen-activated protein kinase signal transduction pathways activated by stress and inflammation. Physiol. Rev. 2001, 81, 807-869. [PubMed]

50. Nishimoto, S.; Nishida, E. MAPK signalling: ERK5 versus ERK1/2. EMBO Rep. 2006, 7, 782-786. [CrossRef] [PubMed]

51. Davis, R.J. Signal transduction by the JNK group of MAP kinases. Cell 2000, 103, 239-252. [CrossRef]

52. Derijard, B.; Raingeaud, J.; Barrett, T.; Wu, I.H.; Han, J.; Ulevitch, R.J.; Davis, R.J. Independent human MAP-kinase signal transduction pathways defined by MEK and MKK isoforms. Science 1995, 267, 682-685. [CrossRef] [PubMed]

53. Raingeaud, J.; Whitmarsh, A.J.; Barrett, T.; Dérijard, B.; Davis, R.J. MKK3- and MKK6-regulated gene expression is mediated by the p38 mitogen-activated protein kinase signal transduction pathway. Mol. Cell. Biol. 1996, 16, 1247-1255. [CrossRef] [PubMed]

54. Tournier, C.; Dong, C.; Turner, T.K.; Jones, S.N.; Flavell, R.A.; Davis, R.J. MKK7 is an essential component of the JNK signal transduction pathway activated by proinflammatory cytokines. Genes Dev. 2001, 15, 1419-1426. [CrossRef] [PubMed]

55. Zarubin, T.; Han, J. Activation and signaling of the p38 MAP kinase pathway. Cell Res. 2005, 15, 11-18. [CrossRef] [PubMed]

56. Bulavin, D.V.; Saito, S.; Hollander, M.C.; Sakaguchi, K.; Anderson, C.W.; Appella, E.; Fornace, A.J. Phosphorylation of human p53 by p38 kinase coordinates N-terminal phosphorylation and apoptosis in response to UV radiation. EMBO J. 1999, 18, 6845-6854. [CrossRef] [PubMed]

57. Wang, X.; Ron, D. Stress-induced phosphorylation and activation of the transcription factor CHOP (GADD153) by p38 MAP kinase. Science 1996, 272, 1347-1349. [CrossRef] [PubMed] 
58. Smeal, T.; Binetruy, B.; Mercola, D.A.; Birrer, M.; Karin, M. Oncogenic and transcriptional cooperation with Ha-Ras requires phosphorylation of c-Jun on serines 63 and 73. Nature 1991, 354, 494-496. [CrossRef] [PubMed]

59. Hess, J.; Angel, P.; Schorpp-Kistner, M. AP-1 subunits: Quarrel and harmony among siblings. J. Cell Sci. 2004, 117, 5965-5973. [CrossRef] [PubMed]

60. McGilvray, I.D.; Lu, Z.; Wei, A.C.; Dackiw, A.P.; Marshall, J.C.; Kapus, A.; Levy, G.; Rotstein, O.D. Murine hepatitis virus strain 3 induces the macrophage prothrombinase $f g l-2$ through p 38 mitogen-activated protein kinase activation. J. Biol. Chem. 1998, 273, 32222-32229. [CrossRef] [PubMed]

61. Mizutani, T.; Fukushi, S.; Saijo, M.; Kurane, I.; Morikawa, S. Phosphorylation of p38 MAPK and its downstream targets in SARS coronavirus-infected cells. Biochem. Biophys. Res. Commun. 2004, 319, 1228-1234. [CrossRef] [PubMed]

62. Regan, A.D.; Cohen, R.D.; Whittaker, G.R. Activation of p38 MAPK by feline infectious peritonitis virus regulates pro-inflammatory cytokine production in primary blood-derived feline mononuclear cells. Virology 2009, 384, 135-143. [CrossRef] [PubMed]

63. Liao, Y.; Wang, X.; Huang, M.; Tam, J.P.; Liu, D.X. Regulation of the p38 mitogen-activated protein kinase and dual-specificity phosphatase 1 feedback loop modulates the induction of interleukin 6 and 8 in cells infected with coronavirus infectious bronchitis virus. Virology 2011, 420, 106-116. [CrossRef] [PubMed]

64. Huang, Y.; Ding, L.; Li, Z.; Dai, M.; Zhao, X.; Li, W.; Du, Q.; Xu, X.; Tong, D. Transmissible gastroenteritis virus infection induces cell apoptosis via activation of p53 signalling. J. Gen. Virol. 2013, 94, 1807-1817. [CrossRef] [PubMed]

65. Padhan, K.; Minakshi, R.; Towheed, M.A.B.; Jameel, S. Severe acute respiratory syndrome coronavirus 3a protein activates the mitochondrial death pathway through p38 MAP kinase activation. J. Gen. Virol. 2008, 89, 1960-1969. [CrossRef] [PubMed]

66. Kopecky-Bromberg, S.A.; Martinez-Sobrido, L.; Palese, P. 7a protein of severe acute respiratory syndrome coronavirus inhibits cellular protein synthesis and activates p38 mitogen-activated protein kinase. J. Virol. 2006, 80, 785-793. [CrossRef] [PubMed]

67. Banerjee, S.; Narayanan, K.; Mizutani, T.; Makino, S. Murine coronavirus replication-induced p38 mitogen-activated protein kinase activation promotes interleukin-6 production and virus replication in cultured cells. J. Virol. 2002, 76, 5937-5948. [CrossRef] [PubMed]

68. Xu, G.-L.; Chen, J.; Yang, F.; Li, G.-Q.; Zheng, L.-X.; Wu, Y.-Z. C5a/C5aR pathway is essential for the pathogenesis of murine viral fulminant hepatitis by way of potentiating Fgl2/fibroleukin expression. Hepatology 2014, 60, 114-124. [CrossRef] [PubMed]

69. Jimenez-Guardeño, J.M.; Nieto-Torres, J.L.; DeDiego, M.L.; Regla-Nava, J.A.; Fernandez-Delgado, R.; Castaño-Rodriguez, C.; Enjuanes, L. The PDZ-binding motif of severe acute respiratory syndrome coronavirus envelope protein is a determinant of viral pathogenesis. PLoS Pathog. 2014, 10, e1004320. [CrossRef] [PubMed]

70. Surjit, M.; Liu, B.; Kumar, P.; Chow, V.T.K.; Lal, S.K. The nucleocapsid protein of the SARS coronavirus is capable of self-association through a C-terminal 209 amino acid interaction domain. Biochem. Biophys. Res. Commun. 2004, 317, 1030-1036. [CrossRef] [PubMed]

71. Varshney, B.; Lal, S.K. SARS-CoV accessory protein 3b induces AP-1 transcriptional activity through activation of JNK and ERK pathways. Biochemistry 2011, 50, 5419-5425. [CrossRef] [PubMed]

72. Kanzawa, N.; Nishigaki, K.; Hayashi, T.; Ishii, Y.; Furukawa, S.; Niiro, A.; Yasui, F.; Kohara, M.; Morita, K.; Matsushima, K.; et al. Augmentation of chemokine production by severe acute respiratory syndrome coronavirus 3a/X1 and 7a/X4 proteins through NF-kB activation. FEBS Lett. 2006, 580, 6807-6812. [CrossRef] [PubMed]

73. Mizutani, T.; Fukushi, S.; Saijo, M.; Kurane, I.; Morikawa, S. JNK and PI3k/Akt signaling pathways are required for establishing persistent SARS-CoV infection in Vero E6 cells. Biochim. Biophys. Acta 2005, 1741, 4-10. [CrossRef] [PubMed]

74. Mizutani, T.; Fukushi, S.; Ishii, K.; Sasaki, Y.; Kenri, T.; Saijo, M.; Kanaji, Y.; Shirota, K.; Kurane, I.; Morikawa, S. Mechanisms of establishment of persistent SARS-CoV-infected cells. Biochem. Biophys. Res. Commun. 2006, 347, 261-265. [CrossRef] [PubMed]

75. Yu, D.; Zhu, H.; Liu, Y.; Cao, J.; Zhang, X. Regulation of proinflammatory cytokine expression in primary mouse astrocytes by coronavirus infection. J. Virol. 2009, 83, 12204-12214. [CrossRef] [PubMed] 
76. Chang, Y.-J.; Liu, C.Y.Y.; Chiang, B.-L.; Chao, Y.-C.; Chen, C.-C. Induction of IL-8 release in lung cells via activator protein-1 by recombinant baculovirus displaying severe acute respiratory syndrome-coronavirus spike proteins: Identification of two functional regions. J. Immunol. 2004, 173, 7602-7614. [CrossRef] [PubMed]

77. Liu, M.; Yang, Y.; Gu, C.; Yue, Y.; Wu, K.K.; Wu, J.; Zhu, Y. Spike protein of SARS-CoV stimulates cyclooxygenase-2 expression via both calcium-dependent and calcium-independent protein kinase $\mathrm{C}$ pathways. FASEB J. 2007, 21, 1586-1596. [CrossRef] [PubMed]

78. Pasternak, A.O.; Spaan, W.J.; Snijder, E.J. Nidovirus transcription: How to make sense...? J. Gen. Virol. 2006, 87, 1403-1421. [CrossRef] [PubMed]

79. Tahara, S.M.; Dietlin, T.A.; Bergmann, C.C.; Nelson, G.W.; Kyuwa, S.; Anthony, R.P.; Stohlman, S.A. Coronavirus translational regulation: Leader affects mRNA efficiency. Virology 1994, 202, 621-630. [CrossRef] [PubMed]

80. Tahara, S.M.; Dietlin, T.A.; Nelson, G.W.; Stohlman, S.A.; Manno, D.J. Mouse hepatitis virus nucleocapsid protein as a translational effector of viral mRNAs. Adv. Exp. Med. Biol. 1998, 440, 313-318. [PubMed]

81. Hofmann, M.A.; Chang, R.Y.; Ku, S.; Brian, D.A. Leader-mRNA junction sequences are unique for each subgenomic mRNA species in the bovine coronavirus and remain so throughout persistent infection. Virology 1993, 196, 163-171. [CrossRef] [PubMed]

82. Hofmann, M.A.; Sethna, P.B.; Brian, D.A. Bovine coronavirus mRNA replication continues throughout persistent infection in cell culture. J. Virol. 1990, 64, 4108-4114. [PubMed]

83. Senanayake, S.D.; Brian, D.A. Translation from the $5^{\prime}$ untranslated region (UTR) of mRNA 1 is repressed, but that from the $5^{\prime}$ UTR of mRNA 7 is stimulated in coronavirus-infected cells. J. Virol. 1999, 73, 8003-8009. [PubMed]

84. Kamitani, W.; Narayanan, K.; Huang, C.; Lokugamage, K.; Ikegami, T.; Ito, N.; Kubo, H.; Makino, S. Severe acute respiratory syndrome coronavirus nsp1 protein suppresses host gene expression by promoting host mRNA degradation. Proc. Natl. Acad. Sci. USA 2006, 103, 12885-12890. [CrossRef] [PubMed]

85. Narayanan, K.; Huang, C.; Lokugamage, K.; Kamitani, W.; Ikegami, T.; Tseng, C.T.; Makino, S. Severe acute respiratory syndrome coronavirus nsp1 suppresses host gene expression, including that of type I interferon, in infected cells. J. Virol. 2008, 82, 4471-4479. [CrossRef] [PubMed]

86. Lokugamage, K.G.; Narayanan, K.; Huang, C.; Makino, S. Severe acute respiratory syndrome coronavirus protein nsp1 is a novel eukaryotic translation inhibitor that represses multiple steps of translation initiation. J. Virol. 2012, 86, 13598-13608. [CrossRef] [PubMed]

87. Tanaka, T.; Kamitani, W.; DeDiego, M.L.; Enjuanes, L.; Matsuura, Y. Severe acute respiratory syndrome coronavirus nsp1 facilitates efficient propagation in cells through a specific translational shutoff of host mRNA. J. Virol. 2012, 86, 11128-11137. [CrossRef] [PubMed]

88. Lokugamage, K.G.; Narayanan, K.; Nakagawa, K.; Terasaki, K.; Ramirez, S.I.; Tseng, C.T.; Makino, S. Middle east respiratory syndrome coronavirus nsp1 inhibits host gene expression by selectively targeting mRNAs transcribed in the nucleus while sparing mRNAs of cytoplasmic origin. J. Virol. 2015, 89, 10970-10981. [CrossRef] [PubMed]

89. Rottier, P.J.; Horzinek, M.C.; van der Zeijst, B.A. Viral protein synthesis in mouse hepatitis virus strain A59-infected cells: Effect of tunicamycin. J. Virol. 1981, 40, 350-357. [PubMed]

90. Hilton, A.; Mizzen, L.; MacIntyre, G.; Cheley, S.; Anderson, R. Translational control in murine hepatitis virus infection. J. Gen. Virol. 1986, 67, 923-932. [CrossRef] [PubMed]

91. Huang, C.; Lokugamage, K.G.; Rozovics, J.M.; Narayanan, K.; Semler, B.L.; Makino, S. Alphacoronavirus transmissible gastroenteritis virus nsp1 protein suppresses protein translation in mammalian cells and in cell-free HeLa cell extracts but not in rabbit reticulocyte lysate. J. Virol. 2011, 85, 638-643. [CrossRef] [PubMed]

92. Jansson, A.M. Structure of alphacoronavirus transmissible gastroenteritis virus nsp1 has implications for coronavirus nsp1 function and evolution. J. Virol. 2013, 87, 2949-2955. [CrossRef] [PubMed]

93. Zhang, Q.; Shi, K.; Yoo, D. Suppression of type I interferon production by porcine epidemic diarrhea virus and degradation of CREB-binding protein by nsp1. Virology 2016, 489, 252-268. [CrossRef] [PubMed]

94. Tohya, Y.; Narayanan, K.; Kamitani, W.; Huang, C.; Lokugamage, K.; Makino, S. Suppression of host gene expression by nsp1 proteins of group 2 bat coronaviruses. J. Virol. 2009, 83, 5282-5288. [CrossRef] [PubMed] 
95. Brostrom, C.O.; Brostrom, M.A. Regulation of translational initiation during cellular responses to stress. Prog. Nucl. Acid Res. Mol. Biol. 1998, 58, 79-125.

96. Clemens, M.J. Initiation factor eIF2 $\alpha$ phosphorylation in stress responses and apoptosis. Prog. Mol. Subcell. Biol. 2001, 27, 57-89. [PubMed]

97. Beattie, E.; Denzler, K.L.; Tartaglia, J.; Perkus, M.E.; Paoletti, E.; Jacobs, B.L. Reversal of the interferon-sensitive phenotype of a vaccinia virus lacking E3L by expression of the reovirus S4 gene. J. Virol. 1995, 69, 499-505. [PubMed]

98. Proud, C.G. eIF2 and the control of cell physiology. Semin. Cell Dev. Biol. 2005, 16, 3-12. [CrossRef] [PubMed]

99. Vattem, K.M.; Staschke, K.A.; Wek, R.C. Mechanism of activation of the double-stranded-RNA-dependent protein kinase, PKR: Role of dimerization and cellular localization in the stimulation of PKR phosphorylation of eukaryotic initiation factor-2 (eIF2). Eur. J. Biochem. 2001, 268, 3674-3684. [CrossRef] [PubMed]

100. Sood, R.; Porter, A.C.; Ma, K.; Quilliam, L.A.; Wek, R.C. Pancreatic eukaryotic initiation factor-2 $\alpha$ kinase (PEK) homologues in humans, Drosophila melanogaster and Caenorhabditis elegans that mediate translational control in response to endoplasmic reticulum stress. Biochem. J. 2000, 346, 281-293. [CrossRef] [PubMed]

101. Rojas, M.; Vasconcelos, G.; Dever, T.E. An eIF2 $\alpha$-binding motif in protein phosphatase 1 subunit GADD34 and its viral orthologs is required to promote dephosphorylation of eIF2 $\alpha$. Proc. Natl. Acad. Sci. USA 2015, 112, E3466-E3475. [CrossRef] [PubMed]

102. Raaben, M.; Groot Koerkamp, M.J.; Rottier, P.J.; de Haan, C.A. Mouse hepatitis coronavirus replication induces host translational shutoff and mRNA decay, with concomitant formation of stress granules and processing bodies. Cell. Microbiol. 2007, 9, 2218-2229. [CrossRef] [PubMed]

103. Banerjee, S.; An, S.; Zhou, A.; Silverman, R.H.; Makino, S. RNase L-independent specific $28 \mathrm{~S}$ rRNA cleavage in murine coronavirus-infected cells. J. Virol. 2000, 74, 8793-8802. [CrossRef] [PubMed]

104. Cruz, J.L.; Sola, I.; Becares, M.; Alberca, B.; Plana, J.; Enjuanes, L.; Zuniga, S. Coronavirus gene 7 counteracts host defenses and modulates virus virulence. PLoS Pathog. 2011, 7, e1002090. [CrossRef] [PubMed]

105. Kamitani, W.; Huang, C.; Narayanan, K.; Lokugamage, K.G.; Makino, S. A two-pronged strategy to suppress host protein synthesis by SARS coronavirus Nsp1 protein. Nat. Struct. Mol. Biol. 2009, 16, 1134-1140. [CrossRef] [PubMed]

106. Huang, C.; Lokugamage, K.G.; Rozovics, J.M.; Narayanan, K.; Semler, B.L.; Makino, S. SARS coronavirus $\mathrm{nsp} 1$ protein induces template-dependent endonucleolytic cleavage of mRNAs: Viral mRNAs are resistant to nsp1-induced RNA cleavage. PLoS Pathog. 2011, 7, e1002433. [CrossRef] [PubMed]

107. Wathelet, M.G.; Orr, M.; Frieman, M.B.; Baric, R.S. Severe acute respiratory syndrome coronavirus evades antiviral signaling: Role of nsp1 and rational design of an attenuated strain. J. Virol. 2007, 81, 11620-11633. [CrossRef] [PubMed]

108. Zust, R.; Cervantes-Barragan, L.; Kuri, T.; Blakqori, G.; Weber, F.; Ludewig, B.; Thiel, V. Coronavirus non-structural protein 1 is a major pathogenicity factor: Implications for the rational design of coronavirus vaccines. PLoS Pathog. 2007, 3, e109. [CrossRef] [PubMed]

109. Zhang, R.; Li, Y.; Cowley, T.J.; Steinbrenner, A.D.; Phillips, J.M.; Yount, B.L.; Baric, R.S.; Weiss, S.R. The nsp1, nsp13, and M proteins contribute to the hepatotropism of murine coronavirus JHM.WU. J. Virol. 2015, 89, 3598-3609. [CrossRef] [PubMed]

110. Lei, L.; Ying, S.; Baojun, L.; Yi, Y.; Xiang, H.; Wenli, S.; Zounan, S.; Deyin, G.; Qingyu, Z.; Jingmei, L.; et al. Attenuation of mouse hepatitis virus by deletion of the LLRKxGxKG region of Nsp1. PLoS ONE 2013, 8, e61166. [CrossRef] [PubMed]

111. Wang, Y.; Shi, H.; Rigolet, P.; Wu, N.; Zhu, L.; Xi, X.G.; Vabret, A.; Wang, X.; Wang, T. Nsp1 proteins of group I and SARS coronaviruses share structural and functional similarities. Infect. Genet. Evol. 2010, 10, 919-924. [CrossRef] [PubMed]

(C) 2016 by the authors; licensee MDPI, Basel, Switzerland. This article is an open access article distributed under the terms and conditions of the Creative Commons Attribution (CC-BY) license (http://creativecommons.org/licenses/by/4.0/). 